\title{
Temporomandibular Disorders and Bruxism Prevalence in a Portuguese Sample ${ }^{\dagger}$
}

\author{
João Belo $^{1}$, André Almeida ${ }^{2,3}$, Paula Moleirinho-Alves ${ }^{3}$ (D) and Catarina Godinho ${ }^{4, *(D)}$ \\ 1 Aluno do $5^{\circ}$ ano do MIMD, Instituto Universitário Egas Moniz, 2829-511 Almada, Portugal; \\ joaopbelo12@gmail.com \\ 2 Centro de Investigação Interdisciplinar Egas Moniz, Egas Moniz-Cooperativa de Ensino Superior CRL, \\ 2829-511 Almada, Portugal; andremarizalmeida@gmail.com \\ 3 Hospital Cuf Tejo, 1350-352 Lisbon, Portugal; paula.m.alves@cuf.pt \\ 4 Grupo de Patologia Médica, Nutrição e Exercício Clínico (PaMNEC), Centro de Investigação \\ Interdisciplinar Egas Moniz, 2829-511 Almada, Portugal \\ * Correspondence: cgodinho@egasmoniz.edu.pt \\ + Presented at the 5th International Congress of CiiEM-Reducing Inequalities in Health and Society, \\ Online, 16-18 June 2021.
}

check for

updates

Citation: Belo, J.; Almeida, A.; Moleirinho-Alves, P.; Godinho, C. Temporomandibular Disorders and Bruxism Prevalence in a Portuguese Sample. Med. Sci. Forum 2021, 5, 37. https://doi.org/10.3390/msf2021005037

Academic Editors: Helena Barroso and Cidália Castro

Published: 22 July 2021

Publisher's Note: MDPI stays neutral with regard to jurisdictional claims in published maps and institutional affiliations.

Copyright: (c) 2021 by the authors. Licensee MDPI, Basel, Switzerland. This article is an open access article distributed under the terms and conditions of the Creative Commons Attribution (CC BY) license (https:// creativecommons.org/licenses/by/ $4.0 /)$.

\begin{abstract}
Temporomandibular disorder (TMD) encompasses a set of disorders involving the masticatory muscles, the temporomandibular joint and associated structures. It is a complex biopsychosocial disorder with several triggering, predisposing and perpetuating factors. In the etiology of TMD, oral parafunctions, namely bruxism, play a relevant role. The study of bruxism is complicated by some taxonomic and diagnostic aspects that have prevented achieving an acceptable standardization of diagnosis. The aim of this study was to analyze the prevalence of temporomandibular disorders and bruxism in a Portuguese sample.
\end{abstract}

Keywords: temporomandibular disorders; bruxism; awake bruxism; sleep bruxism

\section{Introduction}

Temporomandibular disorder (TMD) encompasses a set of disorders involving the masticatory muscles, the temporomandibular joint (TMJ) and associated structures [1]. The prevalence of painful TMD is about $10 \%$ in adults. It is a complex biopsychosocial disorder with several triggering, predisposing and perpetuating factors (macro- or micro-traumas, genetic, epigenetic, environmental, psychological and behavioral). In TMD etiology, oral parafunctions, namely bruxism, play a relevant role [2]. The definition of bruxism has undergone a constant evolution, currently being described as a repetitive and involuntary activity of the masticatory muscles, which is characterized by clenching or grinding of the teeth and/or by bracing (fixing) or thrusting (boosting) of the mandible, with or without dental contact [2].

\section{Materials and Methods}

An online questionnaire was applied using social networks as well as email contacts provided by the researchers. The questionnaire was translated to Portuguese based on a previous study [2]. This questionnaire included questions related to the characterization of TMD and bruxism (awake and sleep), as well as relevant medical history. Data were analyzed by descriptive methodology.

\section{Results and Discussion}

We obtained 256 answers to the questionnaire, consisting of responses from 196 females $(76.56 \%)$ and from participants aged 18-24 (20.70\%), 25-34 (21.88\%), 35-54 (43.75\%), $55-74(12.11 \%)$ and $+75(1.56 \%)$. In Table 1, we can see the results obtained. 
Table 1. TMD and bruxism in a sample of a Portuguese population.

\begin{tabular}{lcc}
\hline \multicolumn{1}{c}{ Question } & Yes & No \\
\hline $\begin{array}{l}\text { Have you ever had pain in your jaw, temple, ear, or in front of your ear on either side? } \\
\text { In the last 30 days, have you had any headaches, which include the area of the }\end{array}$ & $110(42.9 \%)$ & $145(56.6 \%)$ \\
fountains in your head? & $127(49.6 \%)$ & $129(50.3 \%)$ \\
In the last 30 days, have you had any joint sound (or sounds) when you moved or & $98(38.2 \%)$ & $158(61.7 \%)$ \\
used your jaw? & $40(15.6 \%)$ & $215(83.9 \%)$ \\
$\begin{array}{l}\text { During the waking period, do you realize that you grind your teeth? } \\
\text { During the waking period, do you realize that you squeeze your teeth? }\end{array}$ & $142(55.4 \%)$ & $114(44.5 \%)$ \\
$\begin{array}{l}\text { During the waking period do you realize that you push/press the jaw? } \\
\text { Has anyone informed you, or realized, that you grind your teeth or press your jaw }\end{array}$ & $93(36.3 \%)$ & $163(63.6 \%)$ \\
during sleep? & $98(38.2 \%)$ & $158(61.7 \%)$ \\
If you wake up during sleep, do you usually experience discomfort in the lateral & $70(27.3 \%)$ & $186(72.6 \%)$ \\
muscles areas of the face and/or head (masticatory muscles)? & $76(29.6 \%)$ & $180(70.3 \%)$ \\
In the last six months, have you had orofacial pain? & &
\end{tabular}

The key point to discuss is that more than half of the respondents did not notice pain in the jaw, in the temple area, in the ear or in front of the ear on both sides; they also did not notice any joint sound when they moved or used the jaw. As for awake bruxism, more than half of the respondents do not push/press the jaw. On the other hand, regarding the perception of clenching their teeth during the day, the vast majority responded positively. As far as sleep bruxism is concerned, more than half of the respondents stated that they do not notice grinding, pressing their teeth or feeling any discomfort in the muscle areas of the face and/or head (masticatory muscles). Similarly, with a significant difference, the respondents reported that they had no feeling of any kind of orofacial pain in the last 6 months.

Thus, we can conclude that although the values appear to be low regarding the prevalence of temporomandibular dysfunctions and bruxism in the Portuguese population, we have higher numbers compared with those in published studies [3].

Conflicts of Interest: The authors declare no conflict of interest.

\section{References}

1. Leeuw, R.; Klasser, G.D. Orofacial Pain: Guidelines for Assessment, Diagnosis and Management; Quintessence Books: Berlin, Germany, 2013.

2. Verhoeff, M.C.; Lobbezoo, F.; Wetselaar, P.; Aarab, G.; Koutris, M. Parkinson's disease, temporomandibular disorders and bruxism: A pilot study. J. Oral Rehabil. 2018, 45, 854-863. [CrossRef] [PubMed]

3. Almeida, A.; Cebola, P.; Manso, C.; Félix, S.; Maurício, P.; González, J.R. Prevalence of dysfunctional tempormandibular pathology and added jaw pain in periodical occupational medicine consultation at a Private Portuguese Health Services. Ann. Med. 2020, 51 (Suppl. S1), 121. [CrossRef] 